Citation: Hirt, C. and M. Rexer (2015), Earth2014: 1 arc-min shape, topography, bedrock and ice-sheet models available as gridded data and degree-10,800 spherical harmonics, International Journal of Applied Earth Observation and Geoinformation 39, 103-112, doi:10.1016/j.jag.2015.03.001.

\title{
Earth2014: 1 arc-min shape, topography, bedrock and ice-sheet models - available as gridded data and degree-10,800 spherical harmonics
}

\author{
Christian Hirt ${ }^{1,2}$ \\ Email: c.hirt@curtin.edu.au
}

Moritz Rexer ${ }^{2}$

Email: m.rexer@tum.de

${ }^{1}$ Western Australian Geodesy Group \& The Institute for Geoscience Research \& Department of Spatial Sciences, Curtin University Perth, WA, Australia

${ }^{2}$ Institute for Advanced Study \& Institute for Astronomical and Physical Geodesy, TU Munich, Germany

Highlights

- Earth2014 topography, ice, bedrock and shape models constructed at 1arcmin resolution

- Earth2014 relies on SRTM30_PLUS, SRTM V4.1, Bedmap2 and Greenland Bed Topography v3

- Earth2014 suite comprises five topography and shape grid layers, freely available

- Models expanded into degree 10,800 spherical harmonic series for spectral modelling

- Analyses of model characteristics, power spectra, and external comparisons provided

\section{Abstract}

Since the release of the ETOPO1 global Earth topography model through the US NOAA in 2009, new or significantly improved topographic data sets have become available over Antarctica, Greenland and parts of the oceans. Here we present a suite of new 1 arc-min models of Earth's topography, bedrock and ice-sheets constructed as a composite from up-to-date topography models: Earth2014. Our model suite relies on SRTM30_PLUS v9 bathymetry for the base layer, merged with SRTM v4.1 topography over the continents, Bedmap2 over Antarctica and the new Greenland Bedrock Topography (GBT v3). As such, Earth2014 provides substantially improved information of bedrock and topography over Earth's major ice sheets, and more recent bathymetric depth data over the oceans, all merged into readily usable global grids. To satisfy multiple applications of global elevation data, Earth 2014 provides different representations of Earth's relief. These are grids of (1) the physical surface, (2) bedrock (Earth's relief without water and ice masses), (3) bedrock and ice (Earth without water masses), (4) ice sheet thicknesses, (5) rock-equivalent topography (ice and water masses condensed to layers of rock) as mass representation. These models have been transformed into ultra-high degree spherical harmonics, yielding degree 10,800 series expansions of the Earth2014 grids as input for spectral modelling techniques. As further variants, planetary shape models were constructed, providing distances between relief points and the geocenter. The paper describes the input data sets, the development procedures applied, the resulting gridded and spectral 
representations of Earth2014, external validation results and possible applications. The Earth2014 model suite is freely available via http://ddfe.curtin.edu.au/models/Earth2014/

Key words: Earth2014, topography, bathymetry, bedrock, ice sheets, planetary shape, spherical harmonics, composite model

\section{Introduction}

Detailed global information on Earth's relief - encompassing land topography, ocean and lake bathymetry and ice information - is essential for numerous geoscience applications. Examples are as diverse as modelling of the Earth's gravity field (Balmino et al. 2012, Hirt et al. 2013), occurrence analysis of submarine canyons (Harris and Whiteway 2011), and of seamounts (Sandwell et al. 2014a), ocean wave refraction studies (Li et al. 2010), visualisation of relief for geophysical studies (Tape et al. 2010), statistical relief analysis in terms of hypsometric curves and terrain roughness (Melosh 2011), construction of crustal models (Molinari and Morelli 2011, Reguzzoni and Sampietro 2015) and aid in analysis of large-scale geological formation (Stampfli et al. 2013).

In the presence of ocean water and ice coverage, it is not possible to obtain global relief models based on a single homogeneous data source or observation technique (e.g., remote sensing from space). High-resolution digital terrain models, e.g., from the Shuttle Radar Topography Mission (SRTM, e.g., Rabus et al. 2003) or Advanced Spaceborne Thermal Emission and Reflection Radiometer (ASTER, e.g., Tachikawa et al. 2011) mission, provide elevations over land areas only, while digital bathymetry models - from altimetry, echo soundings, or combinations thereof - aim to describe the seafloor or lake bottom topography (Becker et al. 2009). Bedrock elevations (i.e., sub-icetopography) are often obtained from airborne radar measurements (Fretwell et al. 2013).

Earth relief models with global coverage are thus obtained as composites constructed from different data sources over land, water and ice-covered areas. Notable examples of composite models are (1) the 1 arc-min global ETOPO1 (by United States National Oceanic and Atmospheric Administration NOAA, Amante and Eakins 2009), which combines ice thickness data with bathymetry and topography elsewhere, and (2) the 30 arc-sec SRTM30_PLUS (by Scripps Institution of Oceanography, California, USA, Becker et al. 2009) data set as a global merger of altimetry-derived and ship-track bathymetry and SRTM topography. SRTM30_PLUS is provided as one-layer representation, while ETOPO1 comprises two layers of information (bedrock and ice surface heights).

Recently, significantly improved bed, surface and ice thickness data sets have become available with the Bedmap2 (Fretwell et al. 2013) data compilation over Antarctica, and the GBT bedrock topography (Bamber et al. 2013) over Greenland. Further, the SRTM30_PLUS bathymetry has been updated about annually with new depth soundings and/or improved depth estimates from altimetry (Sandwell et al. 2014b). As a result, ETOPO1 is based to some extent on now-outdated data sets over the oceans and ice-covered regions, while SRTM30_PLUS does not yet incorporate recent surface height data over the ice-sheets. However, for many current applications of global relief data, a merged data set representing Earth's surface, ice and bedrock based on recent data would be useful.

This paper presents of suite of new models of Earth's topography, bedrock and ice-sheets constructed as a composite from up-to-date topography models: Earth2014. To satisfy multiple applications of global relief data, Earth2014 provides readily usable grids of (1) the physical surface SUR, (2) bedrock BED (Earth's relief without water and ice masses), (3) topography, bedrock and ice 
TBI (representing Earth without water masses), (4) ice sheet thicknesses ICE, and (5) rock-equivalent topography RET (ice and water masses condensed to layers of rock) as mass representation. These models have been expanded into ultra-high degree spherical harmonics, yielding degree 10,800 series expansions of the Earth2014 grids as input for spectral modelling techniques frequently used in geodesy and geophysics. As further variants, planetary shape models have been constructed, providing distances between relief points and the geocenter. While the topography models (SUR, BED, TBI, and RET) use the mean sea level as vertical datum, the vertical reference of the shape models is the geocenter.

Earth2014 relies on SRTM30_PLUS v9 bathymetry as base layer, merged with SRTM v4.1 topography over the continents, Bedmap2 over Antarctica and the Greenland Bedrock Topography (GBT v3) as input data (Section 2). Section 3 summarizes the data processing applied to yield the Earth 2014 grids. Section 4 characterizes the new relief models, e.g., in terms of geo-statistics, hypsometric curves, and degree variance power spectra, and provides selected 3D visualizations. The Earth2014 global grids are compared against ETOPO1 and SRTM30_PLUS (Section 5), before outlining some applications and drawing conclusions in Section 6.

\section{Input data}

The Earth2014 suite of global relief and topography models is based on four input data sets,

(i) SRTM30_PLUS (Becker et al. 2009) v9 (Dec 2013) bathymetry and topography model,

(ii) the SRTM V4.1 topography (Jarvis et al. 2008) over all land areas between $\pm 60^{\circ}$ latitude,

(iii) Bedmap2 (Fretwell et al. 2013) bedrock, bathymetry and ice thickness data over Antarctica,

(iv) and the Greenland Bedrock Topography (GBT v3, Bamber et al. 2013, Bamber 2014, pers. comm.).

Fig. 1 shows the spatial coverage of the four input data sources. The 30 arc-sec SRTM30_PLUS bathymetry and topography model (Becker et al. 2009) serves as the background layer for Earth 2014. Over land areas, SRTM30_PLUS relies on GTOPO30 topography North of $60^{\circ}$ latitude (Arctic), ICESat ice surface heights (DiMarzio et al. 2007), and SRTM30 topography elsewhere. Over the oceans, SRTM30_PLUS v9 provides depth information based on inverted altimetry gravity data (including new mission data such as Cryosat-2, Jason-1 and Envisat), and a compilation of 300 million soundings (ship-track data). According to Becker et al. (2009), "approximately $10 \%$ of the seafloor has been mapped by echo sounders at a 1-minute resolution" only. The SRTM30_PLUS model also contains bathymetric depth information for Earth's major inland lakes (Superior, Michigan, Huron, Erie, Ontario and Baikal) and the Caspian Sea, which is the relevant data source for Earth2014 inland bathymetry.

Over all (dry) land areas within $60^{\circ}$ North and South latitude, the 7.5 arc-sec $(\sim 250 \mathrm{~m})$ resolution SRTM V4.1 topography model (Jarvis et al. 2008) is the source for Earth2014. SRTM4.1 is a postprocessed SRTM release where voids were filled using advanced interpolation techniques and auxiliary data sets as described in Reuter et al. (2007). 
The 2013 Bedmap2 (Fretwell et al. 2013) data set encompasses 1-km resolution grids of bedrock, surface topography, ice-shelf and ice-sheet thicknesses (mostly from airborne radar) and bathymetric depths over the Antarctic region. Importantly, the Bedmap2 collection incorporates a multitude of new ice thickness and surface elevation data sets originating from surveys conducted or completed since the release of the predecessor Bedmap1 (Lythe et al. 2001).

The Bedmap2 grids substantially improve over earlier Bedmap1 data compilations over Antarctica, as is evident e.g., from independent comparisons against gravimetry (Hirt 2014). Differences in bedrock elevations between Bedmap2 and Bedmap1 are at the level of several $100 \mathrm{~m}$ (up to $1-2 \mathrm{~km}$ maximum), where new ice thickness data has become available (Fretwell et al. 2013, Fig 13 ibid). This is important for comparisons with ETOPO1 which is based on Bedmap1 bedrock (Section 5). Bedmap2 surface heights only marginally rely on the 2007 ICESat measurements, and instead are based on a combination of several newer digital elevation models (e.g., Bamber et al. 2009, Cook et al. 2012) "to exploit the strengths of each" (Fretwell et al. 2013, p381). This is relevant for comparisons of Earth2014 surface heights with SRTM30_PLUS over Antarctica (from 2007 ICESat data), and with ETOPO1 (taken from the Radarsat Antarctic Mapping Project topography v2 released back in 2001) in Section 5. Over Greenland the GBT v3 (Bamber et al. 2013) product is conceptually similar to Bedmap2, in that, it provides grids of ice-thicknesses, surface topography and bedrock/bathymetry based on newly compiled data at $1 \mathrm{~km}$ resolution.

\section{Processing}

\subsection{Grid merging}

Relief information from the four data sets was merged by using SRTM30_PLUS as "base layer", and subsequently inserting the SRTM V4.1, Greenland and Antarctica data sets. In a first step, artifacts detected at about $\sim 3,000$ cells in the V4.1 $250 \mathrm{~m}$ release over parts of Asia were removed and fixed as described in Hirt et al. (2014). Second, SRTM30_PLUS and SRTM V4.1 elevations were combined at the highest possible resolution of 7.5 arc-sec by (i) up-sampling SRTM30_PLUS by a factor 4 using bicubic interpolation, and (ii) inserting SRTM V4.1 elevations where land areas are flagged through the SRTM sea-mask (V4.1).

Third, inland bathymetry (Great Lakes, Baikal, Caspian Sea) was taken into account. Given the input data set "SRTM30_PLUS v9" is not accompanied by a mask grid that would allow identification of inland bathymetry, a procedure to identify inland lake bathymetry had to be developed and applied. We identified inland bathymetry as regions of certain extent (> 2000 cells) with bedrock (SRTM30_PLUS) located at least 5 metres below the surface topography (SRTM V41). Because the SRTM V4.1 and SRTM30_PLUS information is not identical over dry land (among other effects there are oscillating positive and negative discrepancies reflecting the resolution effect of $7.5 \mathrm{arc}-\mathrm{sec}$ vs. 30 arc-sec, and thus additional high-frequency features in the V4.1 data set) it was necessary to impose a minimum size for regions considered as inland lakes. While the criterion applied is pragmatic in our case, it cannot completely extract the lake margins along the inland lake coastlines (e.g., shallow depths were neglected by our criterion). For the lake extraction we applied region growing (e.g., Adams and Bischof 1994), a segmentation technique often used in digital image analysis to extract areas of similar characteristics. As the basic idea of region growing as done here, adjoining cells with systematically positive elevation differences SRTM V4.1 minus SRTM30_PLUS are grouped together through iterative search, yielding regions (segments) considered as lake areas. 
Fourth, using 8x8 cell means, the SRTM V4.1/SRTM30_PLUS merger was down-sampled from 7.5 arcsec to the target resolution 1 arc-min. The resulting grid serves as interim layer for the Earth2014 bedrock layer (BED) and the topography-bedrock-ice layer (TBI), cf. Table 1 for definitions. This SRTM30_PLUS and SRTM V4.1 merging technique has been used in recent gravity field studies (Hirt 2013, Hirt et al. 2013).

Tab. 1 Earth2014 topography models - representations and characteristics

\begin{tabular}{|c|c|c|c|c|c|}
\hline Model & Representation & Dry land & $\begin{array}{l}\text { Major } \\
\text { Lakes }\end{array}$ & Oceans & $\begin{array}{l}\text { Major Ice } \\
\text { sheets }\end{array}$ \\
\hline SUR & $\begin{array}{l}\text { Earth's surface (lower } \\
\text { interface of the atmosphere) }\end{array}$ & Topography & Surface & 0 & Surface \\
\hline BED & $\begin{array}{l}\text { Earth's bedrock (planet } \\
\text { without water and ice) }\end{array}$ & Topography & Bedrock & Bedrock & Bedrock \\
\hline TBI & $\begin{array}{l}\text { Earth's topography, bedrock } \\
\text { and ice (planet without } \\
\text { liquid water) }\end{array}$ & Topography & Bedrock & Bedrock & Surface \\
\hline RET & $\begin{array}{l}\text { Earth's rock-equivalent } \\
\text { topography }\end{array}$ & Topography & RET & RET & RET \\
\hline ICE & Earth's major ice-sheets & 0 & 0 & 0 & Ice thicknesses \\
\hline
\end{tabular}

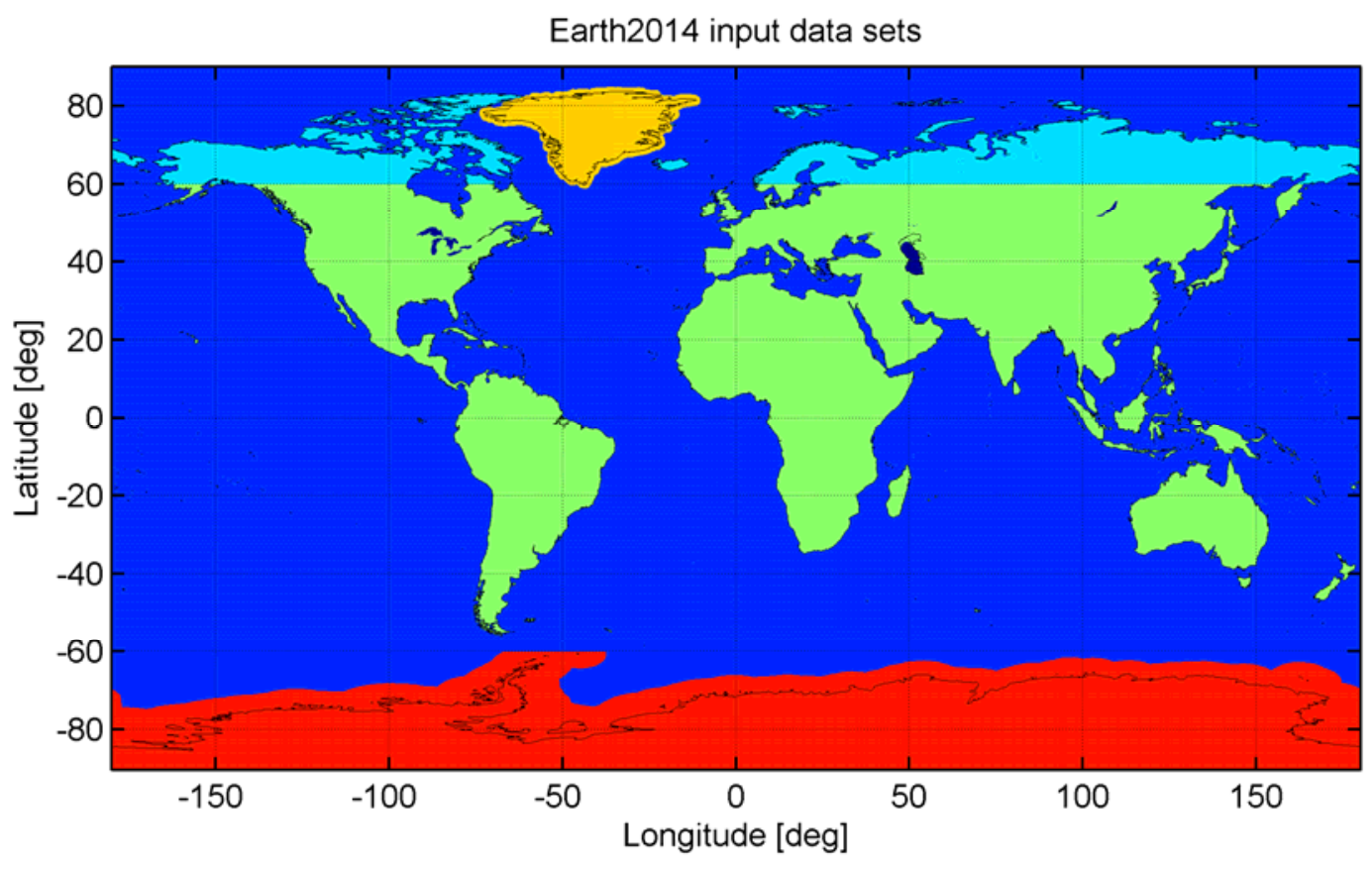

Fig 1. Spatial distribution of input data sets used for the construction of Earth2014 topography models: Bedmap2 (red), GBT_V3 (orange), SRTM V4.1 land topography (green), SRTM_30PLUS ocean bathymetry (blue), SRTM30_PLUS inland bathymetry (dark blue), SRTM30_PLUS land topography (light blue). The SRTM30_PLUS data set serves as the base layer. Elevations from SRTM V4.1 - merged SRTM30_PLUS along coast lines - were inserted over continents and islands. Last, elevations were inserted "as patches" over Antarctica (from Bedmap2) and Greenland (from GBT v3). 


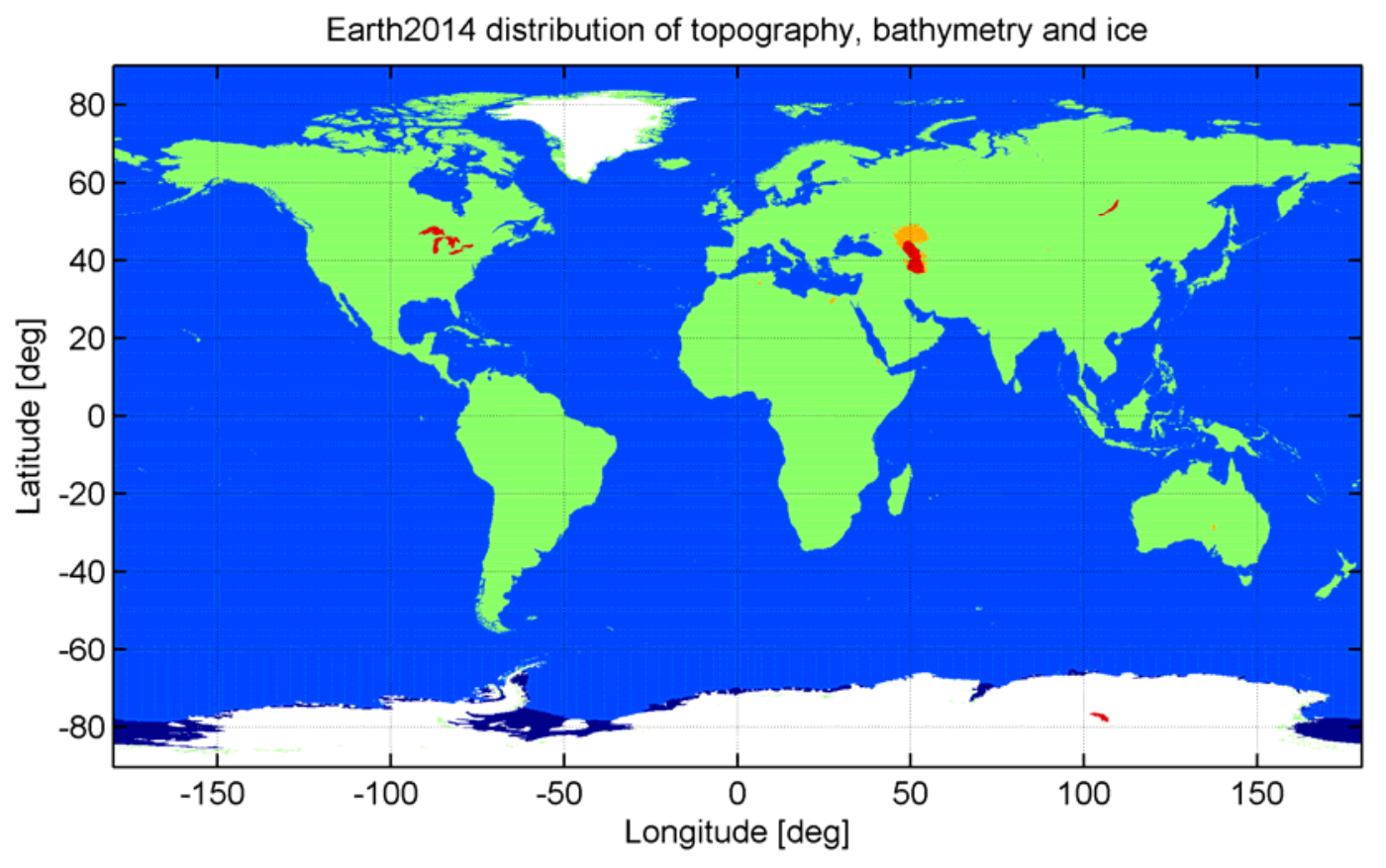

Fig 2. Spatial distribution of main types of terrain in Earth2014. Ice-free land above mean sea level MSL (green) and below MSL (red), ice-covered land (white), ice-covered water (dark blue), oceans (blue), inland water bodies (dark red).

The described procedure was repeated to yield global 1 arc-min grids of Earth's surface SUR (by setting ocean depths to 0 , and replacing inland bathymetry with lake surface heights from SRTM v4.1), and of Earth's rock-eqivalent topography (RET), which is a dedicated Earth2014 layer for mass modelling and gravity applications. RET is a model that represents ice and water masses as massequivalent layers of rock, added to the Earth2014 BED bedrock layer (cf. appendix A for procedures).

While the SRTM data sets and their merger are given in terms of global geodetic latitude-longitude grids, both the Bedmap2 and GBT V3 data grids are in polar stereographic (PS) projection, requiring coordinate transformation from PS to geodetic coordinates (and thus interpolation). Bedrock, surface and RET heights were extracted or computed at $1 \mathrm{~km}$ resolution in PS projection before transforming to geodetic coordinates. As last step, the Bedmap2 and GBT v3 patches (BED, SUR, RET and ICE icesheet thicknesses) were inserted into the SRTM-merger over the areas shown in Fig. 1, giving the Earth2014 global grids at 1 arc-min resolution.

It is important to note that the Bedmap2 data 'patched' into the SRTM V4.1/SRTM30_PLUS merger covers continental Antarctica and a $\sim 400 \mathrm{~km}$ margin (buffer) over the adjoining oceans (Fig. 1) in order to preserve the self-consistency of the Bedmap2 products over land and sea. Along the same lines, a 200km ocean zone surrounding Greenland is taken from GBT v3 and included in Earth 2014. The margin sizes were chosen such that inconsistencies between the SRTM30_PLUS and Bedmap2, and SRTM30_PLUS and GBT V3 bathymetry were kept reasonably small. Along the merging lines (red/blue and orange/blue boundaries in Fig. 1), bathymetry differences of $-1033 /+1017 / 101 \mathrm{~m}$ ( $\mathrm{min} / \mathrm{max} /$ root-mean-square) were observed w.r.t. Bedmap2, and $-464 / 580 / 54 \mathrm{~m}$ w.r.t. GBT v3, reflecting uncertainties in current bathymetry data. In future versions of the Earth relief models, a tapered transition between the data sets could be considered. Not using a tapered transition creates 
artificial features along the merging lines (cf. Fig. 1), which should not be misinterpreted as steps in the seafloor topography.

\subsection{Shape modelling}

For geophysical applications and geo-visualisation, shape models were derived for the various Earth2014 topography models. While the previously described relief models provide elevations of the topography or bedrock with respect to the mean sea level, shape models represent the geometry of the planet via the planetary radius (i.e., distances $r_{P}$ between the geocenter and the surface points). As such, relief and shape models differ by the sum of (a) the ellipsoidal radius, and (b) the geoid height, with the latter being an approximation of the separation between the mean sea level and the ellipsoid surface. Following this definition, radii $r_{P}$ of the Earth2014 shape models were constructed as sum of ellipsoidal radii $r_{E}$, geoid undulations $N$ and relief heights $H_{P}$ (bedrock, surface or RET heights, depending on the model)

$$
r_{P}=r_{E}+N+H_{P}
$$

where ellipsoidal radii are computed via (equation after Claessens 2006)

$$
r_{E}(\varphi)=a \sqrt{\frac{1-e^{2}\left(2-e^{2}\right) \sin ^{2} \varphi}{1-e^{2} \sin ^{2} \varphi}}
$$

with $\varphi$ geodetic latitude, $a$ semi-major axis, and $b$ semi-minor axis of the GRS80 reference ellipsoid (Moritz 2000) and

$$
e^{2}=\frac{a^{2}-b^{2}}{a^{2}}
$$

the first numerical eccentricity squared. Geoid undulations $N$ were obtained from the EGM96 geopotential model (Lemoine et al. 1998) in spectral band of harmonic degrees 2 to 360. EGM96 is used here as model of the geoid because EGM96 provided the vertical reference for the SRTM elevation model. We note that the choice of the geoid model is not too much a concern for global relief modelling, given the differences between present geoid models are mostly at or less the $1 \mathrm{~m}$ level.

\subsection{Transformation to ultra-high degree spherical harmonics}

A convenient way to represent a global topography model is in terms of surface spherical harmonic coefficients (SHCs), see e.g. Balmino et al. (2012) and Pavlis et al. (2012). By evaluating a surface spherical harmonic expansion (SHE) of the discrete form (e.g., Claessens 2006)

$$
H(\phi, \lambda)=\sum_{n=0}^{n \max } \sum_{m=-n}^{n} \overline{T_{n m}} \overline{Y_{n m}}(\phi, \lambda)
$$

with the fully normalized SHCs $\overline{T_{n m}}$ of degree $n$ and order $m$ ( $m<0$ : sine associated; $m \geq 0$ : cosine associated), the elevation $H$ of the topography model can be retrieved at any point on Earth, given by 
geocentric latitude $\phi$ and longitude $\lambda . \overline{Y_{n m}}$ denote the spherical harmonic functions that evaluate the associated Legendre functions (ALFs) depending on the co-latitude, and sine / cosine arguments depending on longitude. Variable $n_{\max }$ is the maximum degree of the model and defines the spatial resolution of the model.

In order to generate the SHCs for the topography grids (from Section 3.1) we make use of a GaussLegendre spherical harmonic analysis (SHA) procedure (see e.g. Sneeuw and Bun, 1996). We extended the SHTOOLS package v2.8 (Wieczorek, 2012) in order to achieve stability of the routines to ultra-high degree. In the original form SHTOOLS v2.8 is restricted to spherical harmonic computations up to degree $\sim 2800$, due to the numerical instability of the ALF implementation (Holmes and Featherstone 2002). We modified the existing ALF computation method with ALFs based on the extended range-arithmetic approach (Fukushima 2012), allowing stable computation of the associated Legendre polynomials up to arbitrary degree and order.

In this work five sets of SHCs of maximum degree and order 10800, corresponding to the resolution of the topography grids ( 1 arc-min), are computed (cf. Section 4.2). Closed loop tests with bandlimited functions of degree 10800 show that the modified SHA procedure works satisfactorily, with maximum errors below $3 \times 10^{-6} \mathrm{~m}$ in the space domain. Note that the functions $H(\phi, \lambda)$ described by the topography grids are usually not band-limited. Therefore the topography grids cannot be exactly represented by a SHE of degree $\mathrm{N}<\infty$. Tests that involve the entire workflow to generate the SHCs and a subsequent spherical harmonic synthesis show a global RMS (root mean square) below 9 $\mathrm{m}$ (maximum errors may exceed $100 \mathrm{~m}$ in steep terrain) for the chosen degree $n_{\max }=10800$. If full topographic information is sought, the data grids should be used instead of the spherical harmonic representations.

\section{Results}

\subsection{Spatial domain}

The main result of this work is the Earth2014 set of 1 arc-min global grid layers which represent the physical surface (SUR), bedrock (BED), bedrock, land topography and ice (TBI), ice sheet thicknesses (ICE), and rock-equivalent topography (RET, also denoted with RET2014 for reasons of consistency for previous releases). The BED layer represents Earth's relief without water and ice masses, and the TBI layer Earth's relief without ocean and lake water masses, they thus differ by the ice sheet thicknesses (and water columns below ice over parts of Antarctica). Table 1 summarizes the differences between the five global Earth2014 grid layers which all provide in approximation physical heights (w.r.t mean sea level) of the relief.

The five grids are self-consistent in that, BED elevations are never larger than SUR or TBI, or RET, or TBI minus ICE elevations, ICE is positive or zero anywhere on Earth, and TBI minus ICE minus BED provides water column heights below ice. Fig. 2 shows a global map of the different terrain types (ice-sheets, ice-shelves, dry land above and below the mean sea level, oceans and lakes) extracted from the input data sets and modelled in Earth2014. Fig. 3 provides 3D visualisations of four Earth 2014 topography models, illustrating the differences between the SUR, BED, TBI and RET representations of Earth's relief. 


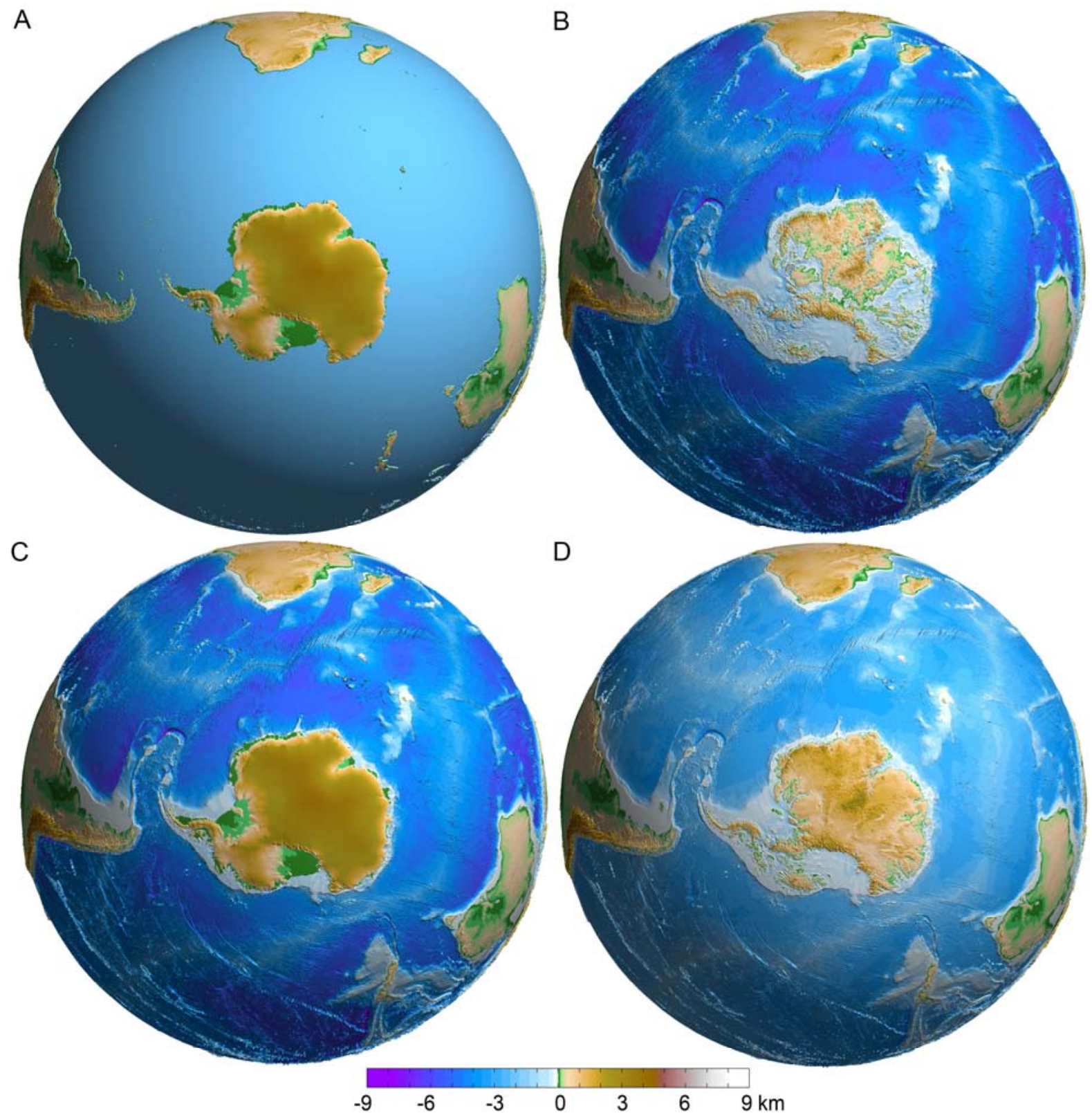

Fig. 3. 3D visualisations of the Earth2014 SUR (panel A), BED (panel B) TBI (Panel C) and RET (panel D) topography layers over the Southern Hemisphere, centred to Antarctica. Visualisations done with the 3D visualisation tools by Bezdek and Sebera (2013).

Table 2 Descriptive statistics of the Earth2014 topography and Earth-shape grids (computed over 10,800 x 21,600 cells with area-weighting), unit in metres

\begin{tabular}{lccccc} 
Model & Min & Max & Range & Mean & STD \\
\hline SUR & -415 & 8212 & 8627 & 231.6 & 635.6 \\
BED & -10847 & 8212 & 19059 & -2443.9 & 2421.1 \\
TBI & -10847 & 8212 & 19059 & -2385.0 & 2508.3 \\
RET & -6660 & 8212 & 14872 & -1413.5 & 1635.5 \\
ICE & 0 & 4613 & 4613 & 58.2 & 374.8 \\
\hline
\end{tabular}


Table 2 reports the descriptive statistics of the Earth2014 grids, whereby the mean and standard deviation (STD) take into account the area size of the individual grid cells to prevent overweighting of polar regions. The minimum and maximum values show that at 1 arc-min grid resolution the actual relief is low-pass filtered, so cannot exactly represent Mount Everest's 8,848 m summit and the 10,911 m depression of the Mariana Trench. The STD values are a measure for the global relief roughness of the Earth2014 grid layers, e.g., $636 \mathrm{~m}$ for the physical surface, and $2421 \mathrm{~m}$ for the bedrock model.
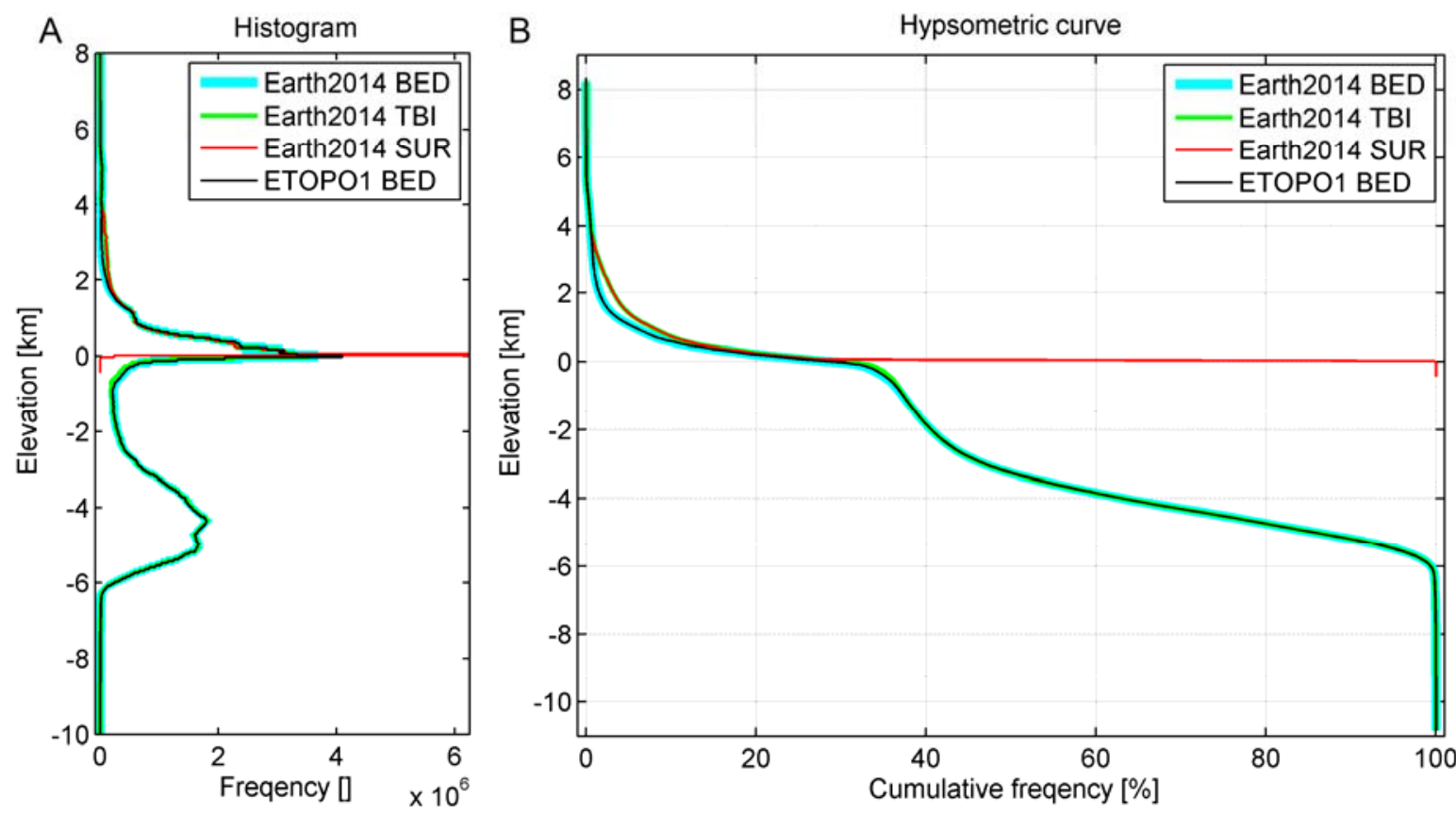

Fig. 4. Histograms of the Earth2014 SUR, BED, TBI and RET models (A) and hypsometric curves (B).

In geostatistics, histograms of the elevation data are commonly used to convey the main model characteristics. Fig. 4 (panel A) the histograms of three selected Earth2014 grid layers (BED, TBI and SUR), along with the ETOPO1 bedrock histogram, and cumulative frequencies (panel B), also known as hypsometric curves (e.g., Melosh 2011) are shown for $50 \mathrm{~m}$ class-widths. Both panels clearly show the accumulation of elevations in the low positive range (near-coastal land), and around -4 to $-5 \mathrm{~km}$ (ocean basins). The ETOPO1 bedrock curve is confirmed by the Earth2014 BED layer, with histogram differences between both models almost indiscernible. Note that this does not deliver information on the geographical distribution of differences between Earth2014 and ETOPO1 (cf. Section 5). The hypsometric curve of the TBI model almost coincides with that of SUR in the positive elevation range, while following the BED curve in the negative range.

\subsection{Spectral domain}

The spherical harmonic analysis procedure (Section 3.3) allowed us to transform the five topographic models (Table 1 ) into the spectral domain. From the SHCs of each model, degree variances $c(n)$ were computed from

$$
c(n)=\sum_{m=-n}^{n}{\overline{T_{n m}}}^{2}
$$


being a measure of the average signal power per harmonic degree (unit square-metres). Fig. 5A shows the degree 10,800 degree variance spectra for Earth2014 SUR, BED, TBI, RET and ICE layers. The power spectra demonstrate that the Earth2014 BED and TBI models possess the largest spectral power at all spatial scales, followed by the RET model. In the absence of seafloor relief, the SUR model shows lesser energy, which is within the expectations. Fig. 5 reveals that the spectra tend to converge towards the high harmonics. We interpret this as a sign of diminishing spectral power in the bathymetry (an estimated $~ 90 \%$ of bathymetric depths in SRTM30_PLUS relies on altimetry-only, which reaches rather $\sim 4$ to 5 rather than 1 arc-min spatial resolution), with the land topography signal becoming dominant in all four representations at short spatial scales. Our interpretation is supported by the spectrum of bathymetric depths, the energy of which is less than that of the land topography for harmonic degrees of $\sim 4000$ and higher (figure not shown here). At a global scale, ICE elevations have the lowest energy.

Table 3. List of generated degree-10800 spherical harmonic models together with the numerical values for the coefficients $A, B$ of the analytical models given in Eq. 6 (or Eq. 7 where the values are marked with the \#symbol).

\begin{tabular}{lcc}
\hline SHC model name & \multicolumn{2}{c}{ Degree variance model parameter } \\
\cline { 2 - 3 } & \multicolumn{1}{c}{$A$} & $B$ \\
\hline SUR2014.shc & $3.9887768863 \mathrm{e3}^{\#}$ & $0.99971521^{\#}$ \\
BED2014.shc & $2.7486337768 \mathrm{e} 7$ & 0.99977702 \\
TBI2014.shc & $2.6815984950 \mathrm{e} 7$ & 0.99977900 \\
RET2014.shc & $1.2830706120 \mathrm{e} 7$ & 0.99984656 \\
ICE2014.shc & $0.0603230884 \mathrm{e} 7$ & 0.99975770 \\
\hline
\end{tabular}
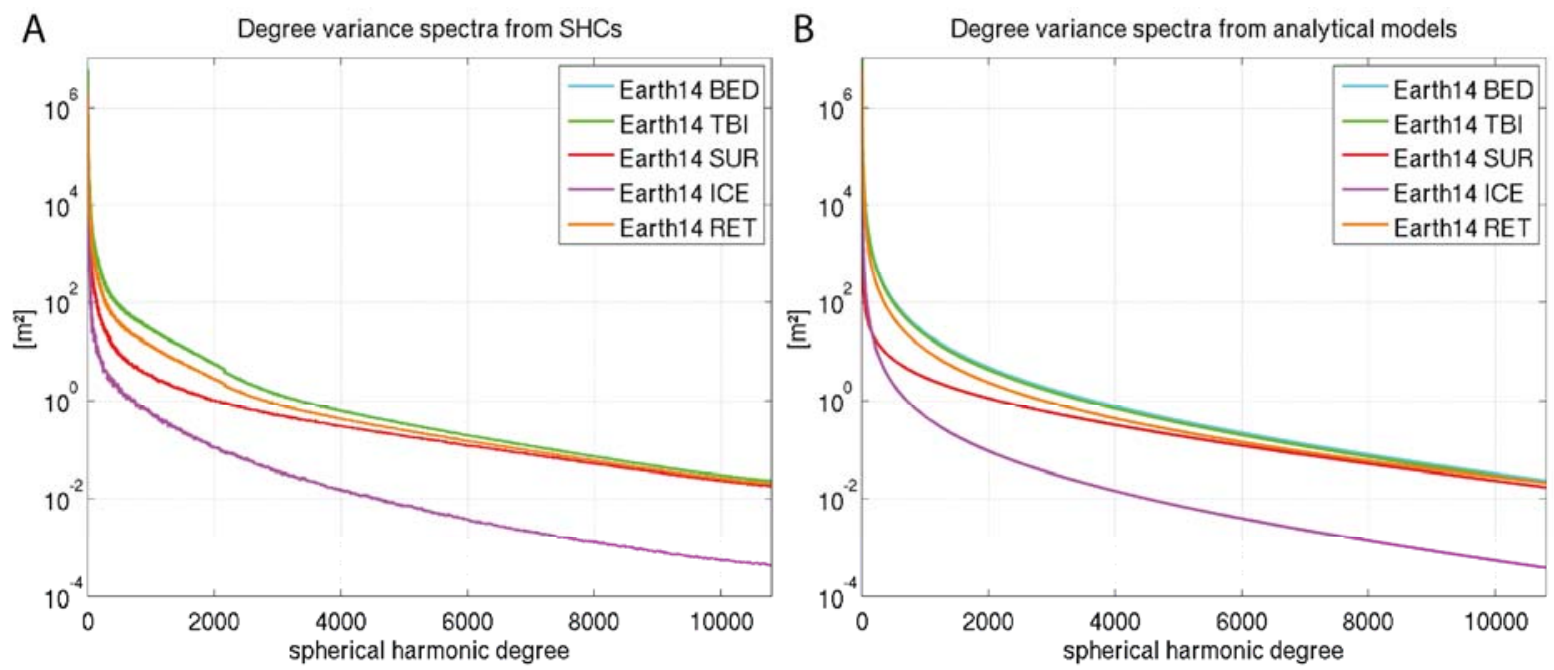

Fig. 5. Degree-variance spectra (A: from SHCs, B: from analytical functions) of the Earth2014 BED (light blue), TBI (green), SUR (red), ICE (magenta) and RET (orange) models to degree 10,800. 
Overall, the curves in Fig. 5 illustrate the decay of the topographic relief with increasing harmonic degree, here for the first time for five representations complete to degree 10,800. We acknowledge work by Balmino et al. (2012) who have provided degree 10,800 spectra for the ETOPO1 topography (one layer only).

Further, we have approximated the degree variances $c(n)$ by analytical models of the type

$$
d(n)=\frac{A \cdot B^{n}}{(n-1)(n-2)}, \quad n \geq 3
$$

or

$$
d^{\prime}(n)=\frac{A \cdot B^{n}}{(n-1)}, \quad n \geq 2
$$

where $A$ and $B$ are the model-specific parameters, estimated through a least-squares fit for each of the five topography model spectra. The numerical values for the $A, B$ coefficients are reported in Table 3. Our analytical degree variance model $d(n)$ is well suited to model the spectra of most of the topography models. The spectrum of the SUR model is the only exception, here Eq. (6) does not well approximate the spectra. Therefore the analytical model $d^{\prime}(n)$ (Eq. 7) has been used in this case (the spectrum at low degrees is still underestimated, but the approximation delivers a good fit for $n>1000)$.

\section{Comparison with ETOPO1 and SRTM30_PLUS}

This section reports results from comparisons between selected Earth2014 grid layers against ETOPO1 and SRTM30_PLUS v9. Earth2014 is formally independent from ETOPO1. However, some indirect relationship exists between the models because of both using land topography from the SRTM mission.

Fig. 6 (panel A) shows the differences between the bedrock layers of Earth2014 and ETOPO1 at 1 arcmin resolution. While there is generally good agreement (often at the level of few metres) over most ice-free and dry land areas, notable discrepancies exist over the oceans, with amplitudes of some $100 \mathrm{~m}$ to $\mathrm{km}$. Given that ETOPO1 is based on a 2008 measured/estimated 2 arc-min bathymetry grid by Scripps Institution of Oceanography (Amante and Eakins 2009, p9), we interpret these discrepancies (somewhat cautiously) as improvements of the seafloor topography in SRTM30_PLUS, and thus in Earth2014. Differences over mountainous regions are likely to reflect different SRTM hole filling procedures (e.g., over Himalayas), inland bathymetry modelled in Earth2014 (e.g., Lake Baikal), but not in ETOPO1, and conversely (e.g., Lake Victoria, modelled in ETOPO1 only).

Further very pronounced differences of several $100 \mathrm{~m}$ amplitude exist over Antarctica (Fig. 7A), which unambiguously reflect the improvements from the 2001 Bedmap1 (used in ETOPO1) to the 2013 Bedmap2 data set (used in Earth2014), also see Fretwell et al. (2013, p389). Along the same lines, differences with somewhat less pronounced amplitudes over Greenland can be considered to reflect errors in the $20015 \mathrm{~km}$-resolution Greenland bedrock data by the National Snow and Ice Data Centre (Bamber et al. 2013, p506) that was used in ETOPO1 (Amante and Eakins 2009, p11). 

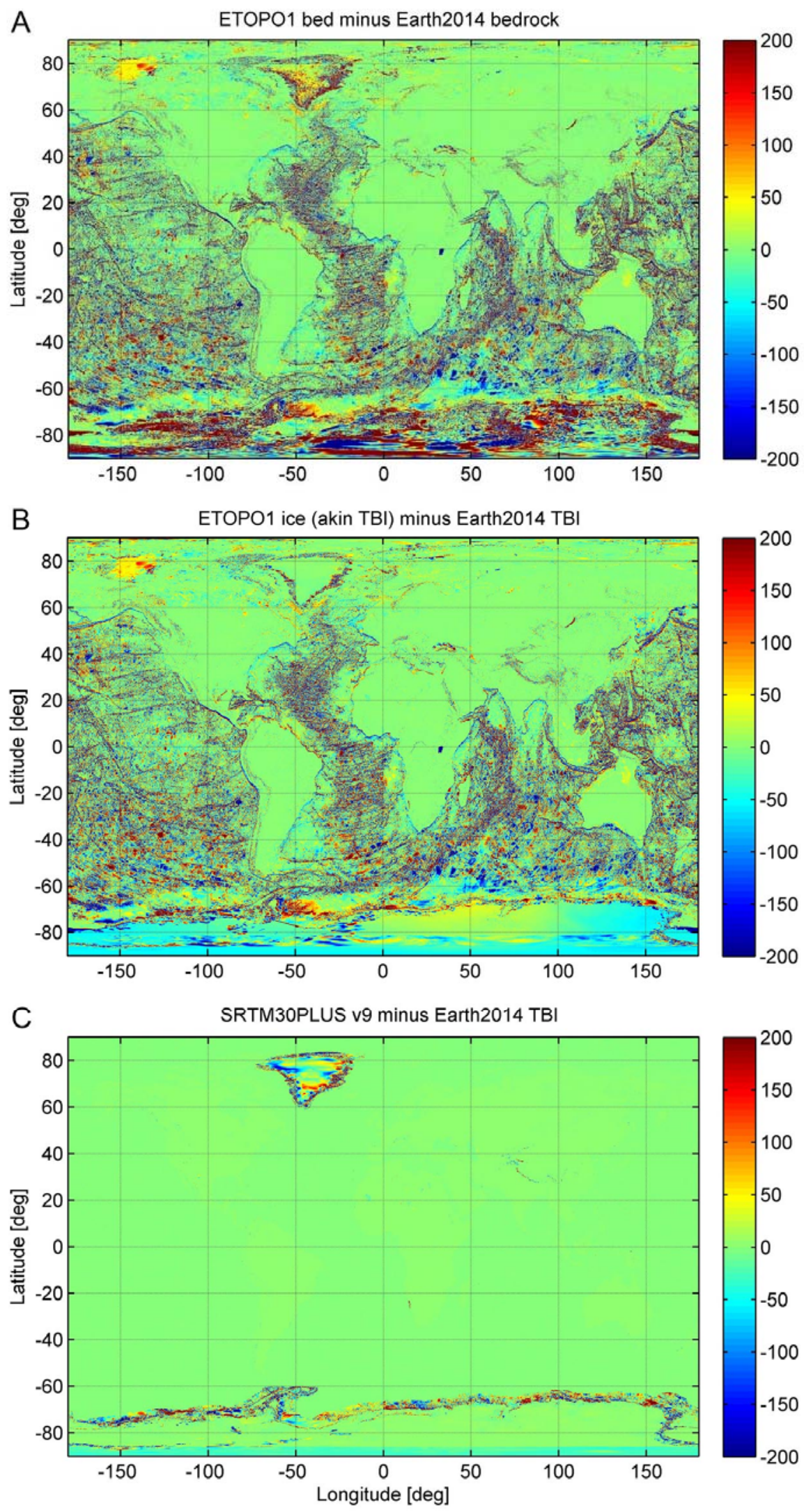

Fig. 6. External comparisons. A: ETOPO1 bed minus Earth2014 BED (min/max/mean/RMS: - 4102/6534/8/139 m), B: ETOPO1 ice minus Earth2014 TBI (-4102/6534/-1/108 m), C: SRTM30_PLUS v9 minus Earth2014 TBI (2773/3045/0/34 m). 
Fig. 6 (panel B) displays the differences between the Earth2014 TBI and the ETOPO ice product, which equally provide topographic elevations over land, ice surface heights over Antarctica and Greenland, and bathymetry elsewhere. The comparisons in Figs. 6A and 6B thus only differ over the ice-sheets. ETOPO1 and Earth2014 ice surface heights are close together over Greenland $(10 \mathrm{~m}$ level over large parts of central Greenland), while often 50-100 m apart over Antarctica. This suggests larger changes in the underlying ice surface data sets over Antarctica than Greenland.

The comparison between SRTM30_PLUS and Earth2014 TBI (Fig. 6C) has mostly internal character. It verifies the Earth2014 processing (mostly zero or m-level differences) over the oceans. Some larger differences exist over mountain areas (indicating different hole-filling procedures between SRTM30 and SRTM V4.1). Over Antarctica and Greenland, and surrounding waters, the comparison in Fig 6C has external character. The largely green areas over continental Antarctica suggest that the ice surface heights are similar in both products (around the South Pole, however, the 2007 ICESat model and thus SRTM30_PLUS deviates by $20 \mathrm{~m}$ from the newer data used in Earth2014).

Notable differences (100s of m amplitude) between Earth2014 and SRTM30_PLUS bathymetry are visible along the Antarctic and Greenland coastlines, where Earth2014 is based on the Bedmap2- and GBT v3-provided bathymetric depth information (Fig. 6C), also see Sect. 3.1. In the absence of true reference data, we cannot attribute the differences to a specific model. Fig. $6 \mathrm{C}$ thus illustrates the differences between the underlying data bases, and probably indicates the error level of up-to-date bathymetry grids, while demonstrating the limitations in our current knowledge of the Earth's seafloor relief compared to the land topography.

\section{Summary, applications and conclusions}

This paper has described the development of the Earth2014 global relief models, which comprise five different layers (surface, bedrock, ice, rock-equivalent topography, and topography-bedrock-icetopography) of relief information. The suite of Earth2014 models is extended by a set of planetary shape models, providing distances to the geocenter, and sets of spherical harmonic coefficients representing the relief models in the spectral domain to ultra-high degree and order of 10,800 . The range of relief representations - elevation and shape grids, and spherical harmonic coefficients should make the new models suitable for a range of gravity and geoscience applications, such as visualisation, geo-statistics and large-scale geophysical or geological studies. The whole Earth2014 suite is freely available via http://ddfe.curtin.edu.au/models/Earth2014/.

Compared to ETOPO1, our Earth2014 global relief model suite provides substantially improved information of bedrock and topography over Earth's major ice sheets, and more recent bathymetric depth data over the oceans, all merged into readily usable global grids. In comparison to SRTM30_PLUS, improvements are certainly over the ice-covered regions, and also related to the multi-layer concept of Earth2014, allowing a more versatile use of the grids. The 1 arc-min Earth2014 model suite replaces Curtin University's 5 arc-min Earth2012 release (http://geodesy.curtin.edu.au/research/models/Earth2012), which is based on older data (among them ETOPO1), and now considered outdated.

A main driver in the development of Earth2014 is its use as a reference model in high-resolution gravity forward modelling (Balmino et al. 2012, Tenzer et al. 2012, Hirt 2012, Claessens and Hirt 2013, Fecher et al. 2015) for geodetic and for geophysical studies (Wieczorek 2007). For full 
flexibility, the model suite is provided in grid representation (for spatial domain modelling), and in terms of harmonic coefficients (for spectral domain modelling), cf. Hirt and Kuhn (2014). The spectral representation of the models may also prove useful for testing and use of recently developed ultrahigh degree synthesis packages (Bucha and Janák 2013) and visualisation tools (Bezdek and Sebera 2013).

The RET layer of Earth2014 has been used to derive spherical harmonic coefficients of the topographic gravitational potential with the method described in Claessens and Hirt (2013). Gravity computed from the Earth2014 topographic gravitational potential has been found to be in closer agreement with observed gravity from the GOCE satellite gravimetry mission (e.g., Pail et al. 2011, van der Meijde et al. 2015) than gravity derived from the ETOPO1 model (cf. detail results in Hirt et al. 2015). These comparisons utilizing GOCE satellite gravimetry as an external validation tool, and thus provide some feedback on the achieved long- and medium-wavelength quality of Earth 2014. Earth2014 will also be used by European Space Agency (ESA) for an update of the GOCE User ToolBox (GUT), where the Earth2014-implied topographic potential provides the topographic reference for Bouguer gravity computations.

While new, improved and more recent data sources of the topographic relief were merged to form the Earth2014 models, we emphasize that current data sets are by all means not free of errors as shown in Section 5. Imperfections or artifacts are to be expected for the lower boundaries of the icesheets (bedrock) over areas where direct ice thickness measurements are absent or scarce. Over large parts of the oceans, the seafloor topography is still scarcely surveyed, and only indirectly known via altimetry at a resolution much less than 1 arc-min. Notwithstanding, ongoing efforts (Sandwell et al. 2014a, Huss and Farinotti 2014) add further detail to bathymetry and bedrock charts and will ultimately yield improved composite global relief models too.

\section{Acknowledgements}

Sincere thanks go to all providers of topography data for making their models freely available, particularly Professores D. Sandwell and J. Bamber, and Doctores A. Jarvis, J. Becker and P. Fretwell. This work received support by the Australian Research Council (ARC grant DP120102441) and by the Institute of Advanced Study (IAS), TU Munich through the German Excellence Science Initiative and the European Union Seventh Framework Programme under grant agreement 291763.

\section{Appendix A}

\section{A1 Computation of rock-equivalent topography (RET)}

To describe the masses of Earth's visible topography, ocean water, lake water and ice masses using a single global grid, RET was developed as special layer of the Earth2014 topography models. RET represents ice and water masses as mass-equivalent layers of rock, based on the mass compression procedure of Rummel et al. (1988), also see Hirt (2013, 2014). The RET compression preserves the ice and water masses, while changing their geometry. As a result, all masses (ice, water, topography) are represented via a single constant mass-density value of topographic rock $\rho_{R}$, simplifying its subsequent use in gravity forward modelling. 
All RET computations were carried at 7.5 arc-sec resolution (SRTM30_PLUS) or $1 \mathrm{~km}$ resolution (Bedmap2, GBT v3, in polar stereographic coordinates). RET heights $H_{\text {RET }}$ from SRTM30_PLUS, Bedmap2 and GBT v3 by compressing water and ice masses into RET using

$$
H_{R E T}=H_{B E D}+\frac{\rho}{\rho_{R}} \Delta H
$$

where $H_{B E D}$ is the bedrock, lake bottom or seafloor height, $\Delta H$ is the thickness of the ice or water body, $\rho_{R}$ is the mass density of topographic rock, and $\rho$ the mass density of the ice or water body (see Table 4 for density values). Over ice-covered water bodies (shelves and Antarctica's lake Vostok), ice and water effects are computed and stacked via the two-layer compression

$$
H_{R E T}=H_{B E D}+\frac{\rho_{W}}{\rho_{R}} \Delta H_{W}+\frac{\rho_{I}}{\rho_{R}} \Delta H_{I} .
$$

Anywhere over dry land, the heights of the topography are identical with RET heights. The spatial distribution of terrain types modelled in RET2014 is shown in Fig. 2.

Table 4. Mass-density values used in RET2014

\begin{tabular}{lll}
\hline Mass body & Symbol & Mass density $\left[\mathrm{kg} \mathrm{m}^{-3}\right]$ \\
\hline Topography & $\rho_{R}$ & 2670 \\
Ocean water & $\rho_{O}$ & 1030 \\
Lake water & $\rho_{L}$ & 1000 \\
Ice water & $\rho_{I}$ & 917 \\
\hline
\end{tabular}

\section{References}

Adams, R., Bischof, L., 1994. Seeded Region Growing. IEEE Transactions on Pattern Analysis and Machine Intelligence archive 16, 641-647.

Amante, C., Eakins, B.W., 2009. ETOPO1 1 Arc-Minute Global Relief Model: Procedures, Data Sources and Analysis. NOAA Technical Memorandum NESDIS NGDC-24, 19 pp.

Balmino, G., Vales, N., Bonvalot, S., Briais, A., 2012. Spherical harmonic modelling to ultra-high degree of Bouguer and isostatic anomalies. J Geod 86, 499-520.

Bamber, J. L., Gomez-Dans, J. L., Griggs, J. A., 2009. A new $1 \mathrm{~km}$ digital elevation model of the Antarctic derived from combined satellite radar and laser data -Part 1: Data and methods. The Cryosphere, 3, 101-111.

Bamber, J.L., Griggs, J.A., Hurkmans, R. T. et al., 2013. A new bed elevation dataset for Greenland. The Cryosphere, 7, 499-510.

Becker, J.J., Sandwell, D.T., Smith, W.H.F., et al., 2009. Global Bathymetry and Elevation Data at 30 Arc Seconds Resolution: SRTM30_PLUS. Mar. Geod. 32, 355-371.

Bezdek, A., Sebera, J., 2013. Matlab script for 3D visualizing geodata on a rotating globe. Comput. Geosci. 56, 127-130.

Bucha, B.,Janák, J., 2013. A MATLAB-based graphical user interface program for computing functionals of the geopotential up to ultra-high degrees and orders. Comput. Geosci. 56, 186-196. 
Claessens S.J., Hirt, C. 2013. Ellipsoidal topographic potential - new solutions for spectral forward gravity modelling of topography with respect to a reference ellipsoid. J. Geophys. Res. - Solid Earth, 118(11), 5991-6002.

Claessens, S.J. 2006. Solutions to Ellipsoidal Boundary Value Problems for Gravity Field Modelling. PhD thesis, Curtin University of Technology, Department of Spatial Sciences, Perth, Australia.

Cook, A. J., Murray, T., Luckman, A., et al. 2012. A new 100-m Digital Elevation Model of the Antarctic Peninsula derived from ASTER Global DEM: methods and accuracy assessment. Earth Syst. Sci. Data, 4, 129-142.

DiMarzio, J. P., et al. 2007. GLAS/ICESat 500mlaser altimetry digital elevation model of Antarctica. National Snow and Ice Data Center.

Fecher, T., Pail, R. Gruber, T. 2015. Global gravity field modeling based on GOCE and complementary gravity data. Intern. J Appl. Earth Obs. Geoinf. 35, 120-127.

Fretwell, P., et al., 2013. Bedmap2: improved ice bed, surface and thickness datasets for Antarctica. The Cryosphere, 7, 375-393.

Fukushima, T., 2012. Numerical computation of spherical harmonics of arbitrary degree and order by extending exponent of floating point numbers, J. Geod. 86, 271-285.

Harris P.T., Whiteway T. 2011. Global distribution of large submarine canyons: Geomorphic differences between active and passive continental margins. Mar. Geol. 285, 69-86.

Hirt C., 2012. Efficient and accurate high-degree spherical harmonic synthesis of gravity field functionals at the Earth's surface using the gradient approach. J. Geod. 86, 729-744.

Hirt C., 2013. RTM gravity forward-modeling using topography/bathymetry data to improve high-degree global geopotential models in the coastal zone. Mar. Geod. 36, 1-20.

Hirt, C., Claessens, S.J., Fecher, T., Kuhn, M., Pail, R., Rexer, M., 2013. New ultra-high resolution picture of Earth's gravity field. Geophys. Res. Lett. 40, 4279-4283.

Hirt, C., 2014. GOCE's view below the ice of Antarctica: Satellite gravimetry confirms improvements in Bedmap2 bedrock knowledge. Geophys. Res. Lett. 41, 5021-5028.

Hirt C., Kuhn, M., 2014. A band-limited topographic mass distribution generates a full-spectrum gravity field gravity forward modelling in the spectral and spatial domain revisited. J. Geophys. Res. - Solid Earth, 119(4), 3646-3661.

Hirt C., Kuhn, M., Claessens, S.J., Pail, R., Seitz, K., Gruber, T., 2014. Study of the Earth's short-scale gravity field using the ERTM2160 gravity model. Comput. Geosci. 73, 71-80.

Hirt C., Rexer, M., Claessens, S., 2015. Topographic evaluation of fifth-generation GOCE gravity field models globally and regionally. Submitted to Newton's Bulletin - Special Issue of the JWG 2.3 between the International Gravity Field Service and the IAG Commission 2.

Holmes, S.A., Featherstone, W.E., 2002. A unified approach to the Clenshaw summation and the recursive computation of very high degree and order normalised associated Legendre functions. J. Geod. 76:279299.

Huss M., Farinotti, D., 2014. A high-resolution bedrock map for the Antarctic Peninsula. The Cryosphere 8: 1261-1273.

Jarvis, A., Reuter, H.I., Nelson, A., Guevara, E., 2008. Hole-filled SRTM for the globe v4.1, Available from the CGIAR-SXI SRTM 90m database at: http://srtm.csi.cgiar.org.

Lemoine, F.G., et al., 1998. The Development of the Joint NASA GSFC and the National Imagery and Mapping Agency (NIMA) Geopotential Model EGM96. NASA Technical Report NASA/TP-1996\8-206861.

Li, X., Lehner, S., Rosenthal, W., 2010. Investigation of Ocean Surface Wave Refraction Using TerraSAR-X DataIEEE Transact. Geosci. Rem. Sens. 48, 2.

Lythe, M. B., Vaughan, D.G., and the Bedmap Consortium, 2001. BEDMAP: A new ice thickness and subglacial topographic model of Antarctica. J. Geophys. Res., 106(B6), 11335-11351.

Melosh, H.J., 2011. Planetary surface processes, Cambridge University Press

Molinari, I., Morelli, A., 2011. EPcrust: a reference crustal model for the European Plate. Geophys. J. Int. 185, 352-364. 
Moritz, H., 2000. Geodetic Reference System 1980. J. Geod. 74, 128-140.

Pail, R., et al. 2011. First GOCE gravity field models derived by three different approaches. J Geod. 85, 819-843.

Pavlis, N.K., Holmes, S.A., Kenyon, S.C. Factor, J.K., 2012. The development and evaluation of the Earth Gravitational Model 2008 (EGM2008), J. Geoph. Res 117(B4), B04406.

Rabus, B., Eineder, M., Roth, A., Bamler, R., 2003. The Shuttle Radar Topography Mission - A New Class of Digital Elevation Models Acquired by Spaceborne Radar. ISPRS J, Photo. Rem. Sens. 57, $241-262$.

Reguzzoni M., Sampietro, D. 2015. GEMMA: An Earth crustal model based on GOCE satellite data. Intern. J Appl. Earth Obs. Geoinf. 35, 31-43.

Reuter H.I., Nelson A., Jarvis A. (2007) An evaluation of void filling interpolation methods for SRTM data. Intern. Journal of Geog. Inform. Sc. 21(9), 983-1008.

Rummel, R., Rapp, R., Sünkel, H., Tscherning, C. 1988. Comparisons of Global Topographic/Isostatic Models To the Earth's Observed Gravity Field. OSU Report 388, Ohio State University.

Sandwell, D.T., et al., 2014a. New global marine gravity model from CryoSat-2 and Jason-1 reveals buried tectonic structure. Science 346(6205), 65-67.

Sandwell, D.T., Olson, C., Jackson, A., Becker, J.J., 2014b. SRTM30_PLUS readme file by Scripps Institution of Oceanography. Available at ftp://topex.ucsd.edu/pub/srtm30 plus/

Sneeuw, N., Bun, R. 1996. Global spherical harmonic computation by two-dimensional Fourier methods. J. Geod, 70:224-232.

Stampfli, G.M., Hochard, C., Vérard, C. et al. 2013. The formation of Pangea, Tectonophys. 593, 1-19.

Tachikawa, T., et al., 2011. ASTER Global Digital Elevation Model v2. https://www.jspacesystems.or.jp/ersdac/GDEM/ver2Validation/Summary_GDEM2_validation_report_fi nal.pdf.

Tape, C., Liu, Q., Maggi, A., Tromp, J., 2010. Seismic tomography of the southern California crust based on spectral-element and adjoint methods. Geophys. J. Int. 180, 433-462.

Tenzer, R., Gladkikh, V., Novák, P., Vajda, P., 2012. Spatial and Spectral Analysis of Refined Gravity Data for Modelling the Crust-Mantle Interface and Mantle-Lithosphere Structure. Surv. Geophys. 33, 817-839.

van der Meijde, M, Pail, R., Bingham, R., Floberghagen, R., 2015. GOCE data, models, and applications: A review. Intern. J. Appl. Earth Obs. Geoinf. 35, 4-15.

Wieczorek, M.A., 2007. The gravity and topography of the terrestrial planets. In: Spohn, T., Schubert, G. (Eds.), Treatise on Geophysics 10. Elsevier-Pergamon, Oxford, 165-989 206.

Wieczorek, M.A., 2012. SHTOOLS - Tools for working with spherical harmonics. Available via shtools.ipgp.fr, downloaded 2014/08/26. 